\title{
A case report: hemothorax caused by rupture of the left atrial appendage
}

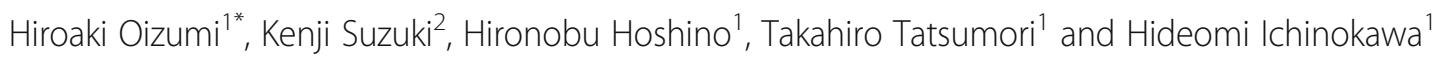

\begin{abstract}
Cardiac rupture is defined as a full-thickness myocardial tear; this injury after blunt chest trauma is rare, and is associated with high mortality. Blunt cardiac rupture typically presents with either cardiac tamponade or massive hemothorax, and is often unrecognized in the context of blunt chest trauma. It is a little known fact that pericardial effusions can decrease due to pericardial lacerations. Hence, cardiac rupture with pericardial lacerations may be easily overlooked especially by chest surgeons. We herein report a case of hemothorax caused by rupture of the left atrial appendage. An 80-year-old male was involved in a motor vehicle crash. We made the diagnosis of hemothorax on the basis of bloody thoracic effusion and left pleural effusion on computed tomography (CT). CT also showed small pericardial effusion in amount and non-displaced rib fractures. We made a tentative diagnosis of intercostal artery injury with rib fractures, we performed left thoracotomy. However, in the operating room, we recognized that cardiac rupture led to massive hemothorax, and that hemothorax was not associated with intercostal artery injury. We repaired left atrial appendage rupture, and his postoperative course was uneventful. Cardiac rupture can present as slight pericardial effusion with hemothorax. On the basis of this case, we propose that cardiac rupture should be considered at the time of hemothorax examination with careful attention to pericardial effusions.
\end{abstract}

Keywords: Hemothorax, Blunt cardiac rupture, Pericardial effusion, Chest surgery

\section{Background}

Cardiac rupture is defined as a full-thickness tear of the cardiac wall, involving all the layers [1]. Blunt cardiac rupture is a rare entity, the frequency of blunt cardiac rupture among hospital trauma admissions ranges from nearly 0.16 to $2 \%$ [2]. Approximately $10 \%$ of patients who suffer blunt injury to the chest have cardiac rupture [3]. An overall mortality of cardiac rupture patients is equal to $93 \%$, and this high incidence of mortality is related to overlooked injuries $[1,4]$. Blunt cardiac rupture characteristically presents with either pericardial tamponade or massive hemothorax [5]. Cardiac rupture patient who have not pericardial tears produce cardiac tamponade. Cardiac rupture patient who have pericardial tears presents as hemothorax, because pericardial tears avoid gathering of intra-pericardial fluid [2, 6].

\footnotetext{
* Correspondence: hoizumi@juntendo.ac.jp

This paper was read at the 69th Annual Scientific Meeting of the Japanese Association for Thoracic Surgery held in Okayama, Japan, September 29, 2016.

'Department of General Thoracic Surgery, Juntendo University Shizuoka Hospital, 1129, Nagaoka, Izunokuni Shizuoka 410-2295, Japan Full list of author information is available at the end of the article
}

When the chest surgeons estimate the origin of bleeding, it is difficult for them to suspect cardiac rupture, and delayed diagnosis leads to poor prognosis. We present a case of blunt cardiac rupture with pericardial lacerations causing hemothorax. Our preoperative assessment of bleeding point was intercostal arteries. However, during our surgery, we recognized that massive hemothorax was related not to rib fractures but to cardiac rupture. We treated the present case as a warning signal for hemothorax.

\section{Case presentation}

An 80-year-old male was involved in a two-car collision as a driver of one of the vehicles. His seat belt was fastened. Physical examination revealed a blood pressure of $70 /$ $30 \mathrm{~mm} \mathrm{Hg}$, a heart rate of $83 \mathrm{bpm}$, oxygen saturation $70 \%$, and decreased vesicular sounds. He was intubated, and he was treated with bilateral thoracotomy tube placement. Bloody thoracic effusion was confirmed by a left thoracocentesis. Approximately $450 \mathrm{ml}$ of sanguineous effusion was drained by left thoracocentesis. He was immediately transported to Juntendo University Shizuoka Hospital. 
Thorough transportation, $200 \mathrm{ml}$ of bloody thoracic effusion was drained subsequently. On arrival, hemoglobin was $10.2 \mathrm{~g} / \mathrm{dl}$. Chest radiograph revealed a normal mediastinum. His Focused Assessment with Sonography for Trauma (FAST) window was negative for fluid except left pleural effusion. Total body CT scan demonstrated left hemothorax with extravasation of contrast and slight pericardial effusion without extravasation of contrast (Fig. 1). Left rib fractures, slight lung contusion in the left lower lobe, and clinically not significant left pneumothorax were also seen by the CT. Fifth and sixth rib fractures were not displaced. The patient was transferred to the intensive care unit, we used nonoperative management in watchful waiting, because hemorrhage volume did not reach the criterion for operability and hemodynamic states were stable at first.

We took care of the patient in ICU for $3 \mathrm{~h}$. We gave transfusion of red blood cells (12U) in order to maintain blood pressure of $100 / 60 \mathrm{~mm} \mathrm{Hg}$ and a heart rate of $70 \mathrm{bpm}$ and to maintain hemoglobin level of at least $10.0 \mathrm{~g} / \mathrm{dl}$ for $3 \mathrm{~h}$. This clinical condition meant hemodynamically unstable, we decided to perform thoracic surgical exploration in the operating room. We predicted that the sources of hemorrhage were the fifth and sixth intercostal arteries and lung contusion in the left lower lobe adjacent rib fractures. We performed left posterolateral thoracotomy, so that we could extend this incision. Thoracotomy revealed bloody effusion and clots, but revealed absence of intercostal artery injury. We identified large amount of fresh blood and clots below the left proximal pulmonary artery, and we identified pericardial lacerations which ran about $30 \mathrm{~mm}$. Then, we extended the incision to anterolateral by about $10 \mathrm{~cm}$. We observed this area carefully to confirm that fresh blood emerged from pericardial space. Then, we dissected pericardium of $50 \mathrm{~mm}$ in diameter in order to detect the source of hemorrhage. We

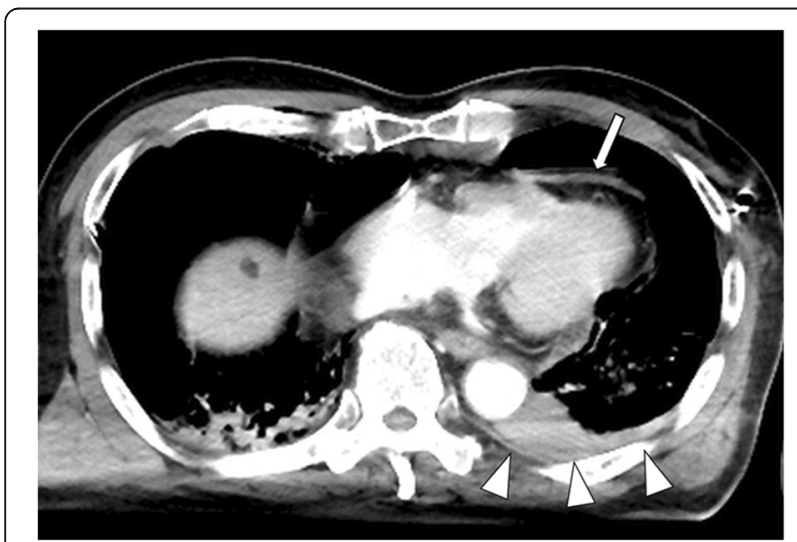

Fig. 1 Initial chest computed tomography. Computed tomogram showed slight pericardial effusion (arrow). Computed tomogram showed left hemothorax with extravasation of contrast (arrow heads) detected that a single left appendage laceration ran about $10 \mathrm{~mm}$. Left appendage bleeding could be controlled by astriction (Fig. 2). We evacuated approximately $1500 \mathrm{ml}$ of fresh blood and clots from the left thoracic cavity. Subsequently, we compressed bleeding point with Tissue Sealing sheet (TachoSil ${ }^{\circ}$, Tokyo, Japan) for $15 \mathrm{~min}$. Exploration of heart and left pleural cavity did not show other injuries such as circumflex coronary artery injury and lung contusion and diaphragm injury. The patient's postoperative course was uncomplicated. Two pleural drains were removed on postoperative day (POD) 7 and on POD 15, respectively. The patient was discharged on POD 49 without a sign of pleural effusion.

\section{Discussion}

Cardiac rupture is an injury to the wall of the heart, usually associated with blunt trauma. The condition is rare, occurring in less than $2 \%$ of trauma patients in most reports, and the mortality remains high, which is generally attributed to failure to diagnose the condition. Quick diagnosis and repair of cardiac rupture are significant to the optimization of outcome [7].

Cardiac rupture is classified into two categories depending on pericardial laceration. Thirty percent of

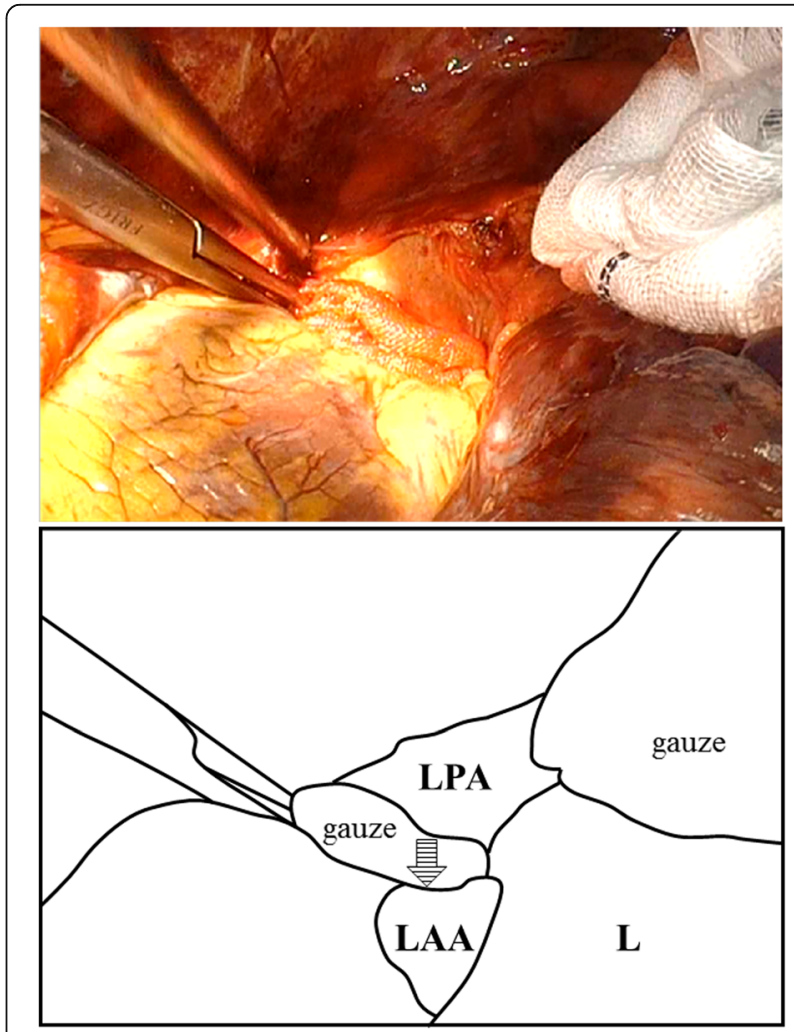

Fig. 2 Intraoperative photograph and its schematic illustration. Left appendage bleeding could be controlled by astriction. Bleeding point (arrow). LAA, left atrial appendage; LPA, left pulmonary artery; L, Lung 
cardiac ruptures are accompanied with pericardial lacerations [8], which leads to hemothorax. Seventy percent of the cardiac ruptures are accompanied with cardiac tamponade. Usually, chest surgeons perform examinations of hemothorax at emergency department. Thus, chest surgeons must recognize the possibility of cardiac rupture with pericardial lacerations, which can produce a clinical picture of hemothorax.

This patient course provided one important clinical suggestion. Pericardial effusion is useful for building clinical reasoning. We can suspect cardiac rupture as the cause of hemothorax based on pericardial effusion, even if those are small in amount. Cardiac rupture patients who have pericardial tears present as hemothorax, because pericardial lacerations avoid gathering of intrapericardial fluid $[2,6]$. To the best of our knowledge, 11 previous alive cases of blunt cardiac rupture with concurrent hemothorax have been reported (Table 1). Pericardial effusion on computed tomography (CT) was detected in six cases (54\%). The other reports (46\%) did not mention existence or non-existence of pericardial effusion. Pericardial effusion may be useful to predict cardiac rupture, even if there are small amount of pericardial effusion. In our case, pericardial effusions are little and there is no extravasation of contrast in the pericardial sac. Contrast collection in the pericardial space has unknown specificity of cardiac rupture in previous reports. Therefore, we must focus on pericardial effusions for rapid diagnosis and treatment when examining a hemothorax patient.

We should immediately examine sources of bleeding through thoracotomy if bleeding points are unclear on
CT. Thoracotomy prove to be both diagnostic and theoretically therapeutic [7]. When the patient has massive bleeding unexplained by the estimated bleeding point, thoracotomy must be done. A question arises as to the option of incision. Once cardiac rupture is strongly suspected, incision is basically rapid, especially in cardiac arrest. Left anterolateral thoracotomy is speedy but it gives very poor access to any cardiac structure except the apex of the left ventricle [9]. In addition, the extension of this incision across the sternum into a clamshell (bilateral anterior thoracotomies) leads to four more bleeding vessels (internal mammary arteries and veins) to contend with [9]. However, in our case, we ought to have chosen the left anterolateral thoracotomy in supine position for an exploration of the left thorax, because the advantage of the left anterolateral thoracotomy is that the incision might be extended to the right if we needed to explore the right thorax.

A query arises about the option of place at which we operate thoracotomy. For the rapidly decompensating or arresting patient, emergency thoracotomy, i.e., left anterolateral thoracotomy in an emergency room has proven to be life-saving [7]. Even if the patient is hemodynamically stable, initial drainage of more than $1000 \mathrm{~mL}$ or constant bleeding is at a rate more than $200 \mathrm{ml} / \mathrm{h}$ for four consecutive hours from an inserted thoracic drain [10], then we must make thoracotomy prior to cardiac arrest. Meanwhile, " $200 \mathrm{ml} / \mathrm{h}$ " is one of the indicators, because in our case drainage function from the chest tube was interfered by clot formation. Moreover, our patient might have a chance to go to the operating room earlier in order to stop the bleeding.

Table 1 Alive cases of hemothorax caused by cardiac rupture

\begin{tabular}{|c|c|c|c|c|c|c|c|}
\hline References & Age/sex & Triggering event & $\begin{array}{l}\text { Pericardial effusion } \\
\text { (on CT) }\end{array}$ & Cardiac lesion & Surgical incision & Operation & Outcome \\
\hline Sliker [11] & $59 / F$ & Motor vehicle crash & + & Left ventricle & Left thoracotomy & NR & Alive \\
\hline Yamaguchi [12] & $59 / \mathrm{M}$ & Motor vehicle crash & NR & Left atrial appendage & Median sternotomy & Suture & Alive \\
\hline Ball [1] & $65 / F$ & Motor vehicle crash & + & Right ventricle & Median sternotomy & Suture & Alive \\
\hline Agathe [4] & $72 / \mathrm{M}$ & Motor vehicle crash & + & Right ventricle & Median sternotomy & Suture & Alive \\
\hline Agathe [4] & $45 / M$ & Motor vehicle crash & + & Right atrial appendage & $\begin{array}{l}\text { Right posterolateral } \\
\text { thoracotomy }\end{array}$ & Suture & Alive \\
\hline Kawahira [13] & $31 / F$ & Fell down the stairs & + & $\begin{array}{l}\text { Right atrial appendage, } \\
\text { right ventricle }\end{array}$ & Median sternotomy & Suture & Alive \\
\hline Murakami [14] & $24 / F$ & Motor vehicle crash & NR & Right atrial appendage & NR & Suture & Alive \\
\hline Kuroda [15] & $71 / F$ & Fell down the stairs & + & Right atrium & Median sternotomy & Suture & Alive \\
\hline Miki [16] & $41 / \mathrm{M}$ & Motorcycle crash & NR & Right atrial appendage & Clamshell & Suture & Alive \\
\hline Miki [16] & $75 / F$ & Motorcycle crash & NR & Left atrial appendage & Clamshell & Suture & Alive \\
\hline Baker [6] & $46 / F$ & Motor vehicle crash & $N R$ & Left atrium, left ventricle & Left thoracotomy & Suture & Alive \\
\hline Our study & 80/M & Motor vehicle crash & + & Left atrial appendage & $\begin{array}{l}\text { Left posterolateral } \\
\text { thoracotomy }\end{array}$ & $\begin{array}{l}\text { Astriction } \\
\text { (suture less) }\end{array}$ & Alive \\
\hline
\end{tabular}




\section{Conclusions}

In summary, we reported a case of hemothorax secondary to blunt cardiac rupture. Pericardial effusion is crucial for suspecting cardiac rupture as a cause of hemothorax, even if it is slight, because cardiac rupture without prompt recognition and proper treatment results in high mortality.

\section{Abbreviations}

CT: Computed tomography; FAST: Focused Assessment with Sonography for Trauma; ICU: Intensive care unit; POD: Postoperative day

\section{Acknowledgements}

We would like to thank Editage (http://www.editage.jp/) for the English language editing.

\section{Authors' contributions}

$\mathrm{HO}$ is the corresponding author and carried out the revision of the manuscript. $\mathrm{HO}, \mathrm{T}$, and $\mathrm{HI}$ carried out the operation. $\mathrm{KS}, \mathrm{HI}$, and $\mathrm{HH}$ carried out the revision of the manuscript. All authors read and approved the final manuscript.

\section{Competing interests}

The authors declare that they have no competing interests.

\section{Consent for publication}

Written informed consent was obtained from the patient for publication of this case report and any accompanying images.

\section{Author details}

'Department of General Thoracic Surgery, Juntendo University Shizuoka Hospital, 1129, Nagaoka, Izunokuni Shizuoka 410-2295, Japan. Department of General Thoracic Surgery, Juntendo University School of Medicine, Tokyo, Japan.

Received: 1 October 2016 Accepted: 23 November 2016

Published online: 26 November 2016

\section{References}

1. Ball CG, Peddle S, Way J, Mulloy RH, Nixon JA, Hameed SM. Blunt cardiac rupture: isolated and asymptomatic. J Trauma. 2005;58:1075-7.

2. Nan YY, Lu MS, Liu KS, Huang YK, Tsai FC, Chu J,, et al. Blunt traumatic cardiac rupture: therapeutic options and outcomes. Injury. 2009:40:938-45.

3. Tanoue K, Sata N, Moriyama Y, Miyahara K. Rupture of the left atrial 'basal' appendage due to blunt trauma in an elderly patient. Eur J Cardiothorac Surg. 2008;34:1118-9.

4. Seguin A, Fadel E, Mussot S, Martin L, Nottin R, Dartevelle P. Blunt rupture of the heart: surgical treatment of three different clinical presentations. J Trauma. 2008;65:1529-33.

5. Powell MA, Lucente FC. Diagnosis and treatment of blunt cardiac rupture. W V Med J. 1997:93:64-7.

6. Baker L, Almadani A, Ball CG. False negative pericardial Focused Assessment with Sonography for Trauma examination following cardiac rupture from blunt thoracic trauma: a case report. J Med Case Rep. 2015;9:155.

7. Teixeira PG, Inaba K, Oncel D, DuBose J, Chan L, Rhee P, et al. Blunt cardiac rupture: a 5-year NTDB analysis. J Trauma. 2009;67:788-91.

8. Ishigami MHSKM, Kitano AMM, Matsuda M. Two cases of right atrial rupture due to blunt chest injury in teenaged drivers after motor vehicle accidents. Jpn J Cardiovasc Surg. 2006;35:295-8.

9. Perchinsky MJ, Long WB, Hill JG. Blunt cardiac rupture. The Emanuel Trauma Center experience. Arch Surg. 1995;130:852-6. discussion 856-857.

10. Hagiwara A, Yanagawa Y, Kaneko N, Takasu A, Hatanaka K, Sakamoto T, et al. Indications for transcatheter arterial embolization in persistent hemothorax caused by blunt trauma. J Trauma. 2008;65:589-94.

11. Sliker CW, Mirvis SE, Shanmuganathan K, Meyer CA. Blunt cardiac rupture: value of contrast-enhanced spiral CT. Clin Radiol. 2000;55:805-8.

12. Shohjiro Yamaquchi NY, Ikeda T, Yamamoto S. A case of left atrium rupture due to nonpenetrating cardiac trauma. Hokuriku J Surg. 2003;22:31-4.

13. Kawahira T, Tsukube T, Ogawa K, Hayashi T, Nakamura M, Kozawa S. Atrial rupture due to blunt chest trauma. Kyobu Geka. 2008;61:533-6.
14. Eiji Murakami HK, Shimabukuro K, Takemura H, Miyauchi T, Takiya H, Matsuhashi N, Toyoda I, Ogura S. Four survivors of blunt cardiac injury without sufficient primary care. J Jpn Assoc Surg Trauma. 2008;22:326-30.

15. Kuroda Y, Toyama S, Yoshimura Y, Kim C, Miyazaki R, Oba E, et al. Right atrial rupture associated with left hemothorax. Kyobu Geka. 2011;64:191-4.

16. Miki T. Clamshell thoracotomy for two cases of blunt traumatic cardiac rupture. Jpn J Cardiovasc Surg. 2014;43:230-3.

\section{Submit your manuscript to a SpringerOpen ${ }^{\circ}$ journal and benefit from:}

- Convenient online submission

- Rigorous peer review

- Immediate publication on acceptance

- Open access: articles freely available online

- High visibility within the field

- Retaining the copyright to your article 